DOI: $10.17976 / j p p s / 2019.03 .12$

\title{
ТРИДЦАТЬ ТРИ РАКУРСА ПОЛИТИЧЕСКОЙ РЕАЛЬНОСТИ
}

\section{С.К. Ознобищев}

ОЗНОБИЩЕВ Сергей Константинович, кандидат исторических наук, зав. сектором, ИМЭМО им. Е.М. Примакова РАН, Москва, email: serko96@gmail.com

Ознобищев С.К. Тридцать три ракурса политической реальности. - Полис. Политические исследования. 2019. № 3. С. 186-191. https://doi.org/10.17976/jpps/2019.03.12

Статья поступила в редакцию: 04.03.2019. Принята к печати: 18.03.2019

\begin{abstract}
Аннотация: Статья анализирует спектр методологических подходов к изучению политических процессов и политической реальности, откликаясь на публикацию фундаментального издания “Современная политическая наука: Методология", объединяющего более тридцати глав, подготовленных четырьмя десятками авторов - ведущими отечественными политологами. Авторы издания фиксируют устойчивый тренд плюрализации методологических установок современной российской политологии. Рассматриваются процессы инкорпорации политической наукой в России ключевых методологических парадигм мировой политологии: позитивизма, бихевиоризма, структурализма, системного анализа, конструктивизма и др. Делается вывод о “мозаичном”, составном характере методологических оснований большинства российских политологических школ и работ и почти полном отсутствии "чистых" методологических линий. В статье обоснован вывод о постепенном достижении современной российской политической наукой состояния широкого методологического плюрализма, открывающего перед исследователями-политологами возможности применения всех главных мировых методологических разработок и парадигм.
\end{abstract}

Ключевые слова: методология, политическая наука, субдисциплины, марксизм, позитивизм, бихевиоризм, конструктивизм, конфликтология, политический реализм, институционализм, научная парадигма.

Происходящие в России и мире турбулентные политические процессы требуют адекватного осмысления и глубокого научного анализа. Сегодня этот анализ востребован не просто как абстрактное упражнение ума, схоластическая полемика маститых ученых, а как практически значимое осмысление нашего общего прошлого, настоящего и будущего.

Мир не стоит на месте - он не только стремительно развивается, но и перекраивает казавшиеся еще вчера незыблемыми законы общественного развития. На обломках старых теорий, не выдержавших испытания временем, формируются новые парадигмы, создающие стимул и основания для теоретических изысканий.

По инициативе руководства Российской ассоциации политической науки (РАПН) и усилиями ее активных участников в 2017-2019 гг. был подготовлен фундаментальный труд “Современная политическая наука: Методология" [Современная политическая... 2019]. 33 главы книги - результат коллективной работы 39 авторов. Трудно назвать значимую фигуру в отечественной политологии, чье имя не значилось бы в оглавлении среди авторов данного научного издания, получившего статус федерального учебника для вузов страны. Двухлетней работой по созданию этого подлинно энциклопедического труда руководили в качестве инициаторов проекта, разработчиков концепции и ответственных соре- 
дакторов широко известные в российском политологическом сообществе ученые: действующий президент РАПН, член Общественной палаты РФ и Общественной палаты Москвы, зав. кафедрой сравнительной политологии МГИМО, доктор политических наук, профессор О.В. Гаман-Голутвина, автор ставших классическими работ в области политической компаративистики и элитологии (см. [Сравнительная политология 2015; Gaman-Golutvina 2018; Gaman-Golutvina 2014; Gaman-Golutvina 2010; Gaman-Golutvina 2009; Gaman-Golutvina 2008 и др.]) и почетный президент РАПН, директор Центра евроатлантической безопасности ИМИ МГИМО, доктор политических наук, профессор А.И. Никитин, известный своими работами в сфере конфликтологии (см. [Никитин 2016; Nikitin, Loukas 2008] и ядерного разоружения [Nikitin 2010] и др.).

Данное издание преемственно продолжает работу Российской ассоциации политической науки по созданию профильных для дисциплины фундаментальных изданий. На книжной полке политолога уже заняли достойное место несколько фундаментальных политологических серий, созданных усилиями членов РАПН: это и изданная в 2015-2016 гг. пятитомная “Российская политическая наука. Истоки и перспективы” [Российская политическая... 2015], и пятитомная "Российская политическая наука" 2008 г. издания [Российская политическая... 2008], и серия "Политическая наука в России: профессионализация, международная интеграция, выведение на уровень мировых стандартов” в десяти книгах (2011-2012), и опубликованная в 2010 г. издательством РОССПЭН уникальная “Библиотека отечественной общественной мысли с древнейших времен до начала XX века” в 117 томах, а также тематические Ежегодники РАПН за два десятка лет (главный редактор серии А.И. Соловьев). Появились и работы, систематизирующие изыскания в отдельных субдисциплинах политической науки: отметим как пример книгу “Институциональная политология" под редакцией С.В. Патрушева [Институциональная политология... 2006]. На базе нескольких десятков региональных университетов России под эгидой РАПН было выполнено исследование "Политическая наука в России: проблемы, направления, школы (1990-2007)” [Политическая наука в России... 2008]. Публикация нескольких серий политологических изданий не только способствовала прояснению истоков и современного состояния отечественной политической науки, но также стала ответом на вызовы современной политики (подробнее см. [Гаман-Голутвина 2016а; Гаман-Голутвина 2016b]). Особенностью рецензируемого издания является избранный ракурс - если вышеперечисленные издания были посвящены анализу эволюции дисциплины и развитию ее школ, направлений, субдисциплин, то новая книга посвящена рассмотрению методологических оснований политической науки, и это в отечественной политологии столь систематически и комплексно сделано впервые.

Разнообразие представленных в книге методологических подходов к объяснению политических процессов заставляет задуматься: а работает ли в политологии парадигмальная теория развития научного знания? Во второй половине XX в. постепенно, но почти повсеместно прежняя модель экспоненциального развития знания была вытеснена парадигмальной, предполагающей не плавное накопление знаний, а периодические скачкообразные смены теоретических парадигм, выступающих методологическим основанием той или иной науки. Эта модель подробно описана в знаменитой работе Т. Куна “Структура научных революций” и дополнена науковедческими выводами П. Фейерабенда о том, что “наука живет сообществами”, другими словами, что в большинстве случаев 
нет единого комплекса научных принципов и теорий, разделяемых всеми учеными планеты, а есть “методологические острова", объединяющие на какой-то исторический период ограниченные во времени и пространстве сообщества ученых, разделяющих общие принципы и видение своей научной области, но не приемлющих методологические принципы других научных сообществ.

Классическим примером такого рода “островов” было господство на протяжении многих десятилетий марксистских методологических принципов во всех общественных науках социалистических стран. Подобно многокомпонентному механизму, где разные по диаметру детали точно входят в пазы друг друга и слаженно вращаются, наличие общих марксистских методологических принципов (теория общественно-экономических формаций, классовой борьбы, революций, определяющего влияния экономического базиса на политическую надстройку и др.) позволяло сотням тысяч исследований и текстов в марксистском научном сообществе монтироваться друг с другом, достраивать и надстраивать конструкцию все новыми смысловыми блоками.

Почти три десятилетия назад в силу известных социально-политических обстоятельств мы оказались на новом научном поле, на котором прежние методологические конструкции были потеснены, частично демонтированы и существенно трансформированы. Для большинства современных российских политологов канул в Лету марксизм-ленинизм как монопольная теория и методологическая парадигма, применимая к реалиям современности, объяснению и истолкованию политической реальности. Но сложилась ли иная, идущая ей на смену методологическая парадигма российской политической науки? Единая - разумеется, нет. Вместо какой-либо одной новой “большой теории” возобладал методологический плюрализм, сам по себе нуждающийся в осмыслении и анализе.

Прежде всего, в течение первого пореформенного десятилетия подверглись осмыслению и переосмыслению существующие зарубежные (почти исключительно западные) теории и методологические направления (знаменитая богатуровская “парадигма освоения”). Позитивизм, бихевиоризм, структурализм, конструктивизм и прочие “-измы”, ранее активно критиковавшиеся, стали "прорастать" и “гостить” в трудах российских политологов. При этом методологических заимствований из, скажем, китайского, иранского или арабского политологического дискурса почти не наблюдалось. Однако можно ли сказать, что в российской политологии сложились постепенно "бихевиористское сообщество”, "Позитивистское сообщество” и подобные им “методологические острова", объединившие на базе своих принципов и методов группы ученых? Пожалуй, и здесь ответ отрицательный. Скорее происходит другое: переплетение в большинстве российских политологических исследований компонентов различных методологий.

Достаточно почитать разделы “Методология исследования" в авторефератах большинства защищенных в постсоветские годы политологических диссертаций. Вы не найдете там прямолинейных утверждений типа “Данная диссертация полностью базируется на методологических принципах позитивизма”... Вместо этого почти повсеместно - перечисление "салата" из "принципов историзма", "методов структурно-функционального и системного анализа", “компаративных исследований”, “политического реализма” и пр. Подобный составной (а можно сказать и иначе: “фрагментарный”) характер применяемых методологических подходов мешает не только цельности каждого отдельного исследования, но и не позволяет большинству исследований сочетаться друг 
с другом в качестве компонентов одной общей объяснительной схемы, интерпретирующей и объясняющей политические явления и процессы.

Именно поэтому одной из важных задач современного этапа развития отечественной политологии является прояснение и упорядочивание ее методологического “фундамента”. Однако если протянуть руку к книжной полке, на которой стоят наиболее известные мировые издания по методологии политической науки, то нетрудно заметить, что и в оксфордских учебниках политической методологии [Box-Steffensmeier, Brady, Collier 2008; Goodin 2009], и в кембриджских “Проблемах и методах изучения политики” [Shapiro, Smith, Masoud 2004], и в опубликованном издательством Нью-Йоркского университета фундаментальном томе "Исследования и методы" [Research and Method 2006], и в свежих комплексных изданиях “Теория и методы политической науки" [Marsh, Stoker, Lowndes 2017], и в "Учебнике по исследовательским методам и приложениям в политической науке” [Keman, Woldendorp 2016] нет сосредоточения на каком-либо ключевом рекомендуемом подходе (и даже позитивизм, ранее безраздельно господствовавший в американской политологии, потеснен), а существует спектр разнотипных методологических принципов.

Обобщая и неизбежно упрощая, можно сказать, что основной задачей отечественных политологических исследований 1990-х годов было (для начала) перекодирование политической реальности в терминах, отличных от отвергнутой марксисткой парадигмы. В течение десятилетия многие университеты России выпустили первые учебники по политологии (отметим учебники под редакцией А.И. Соловьева, А.Ю. Мельвиля и др.), проведены первые крупные комплексные проекты (напомним о масштабном международно-политическом проекте "Политический атлас современности"). Первичное становление понятийно-категориального аппарата отечественной политологии (с адаптацией мирового опыта) было обобщено в издании “Мир политической науки. Категории” под редакцией А.Ю. Мельвиля [Мир политической... 2006].

В 2000-х годах произошло становление многих субдисциплин в обновляемой российской политической науке (таких как электоральные исследования, элитология, конфликтология и др.), нарастивших первоначальные массивы постмарксистских политологических концепций, теорий, книг в отдельных предметных областях. Эти этапы подробно проанализированы в монографии “Структурные трансформации и развитие отечественных школ политологии” [Структурные трансформации... 2015], пятитомной серии "Российская политическая наука: традиции и перспективы” и десятитомном издании РАПН “Политическая наука в России: проблемы становления и механизм развития”. Теперь, к концу третьего постмарксистского десятилетия, в отечественной политологии намечается задача методологического упорядочивания всего комплекса политической науки. Однако очевидно, что это упорядочивание не может заключаться в унификации, в выборе и господстве какой-либо одной методологической парадигмы. Речь идет о другом - о том, что исследователи сознательно выбирают различные, но цельные и применяемые во всей своей полноте и сложности методологические подходы. Важно, чтобы молодые политологи учились понимать внутреннюю логику разнообразных методологических парадигм, их применимость/неприменимость к конкретным предметным областям и задачам исследования.

Эту задачу и помогает решить уникальное научное издание "Современная политическая наука: Методология”, которое последовательно разворачивает перед читателем панораму более чем трех десятков методологических под- 
ходов/парадигм, разработанных в мировой политической науке. Впервые в отечественной научной и учебной литературе столь панорамно и полно анализируется и структурируется каждое методологическое направление, представляются его авторы и их базовые работы.

Задача создания такого труда сегодня более чем своевременна. И коллективу авторов работа определенно удалась. Будем надеяться, что обычно скомканный раздел “Методология исследования” в будущих диссертациях российских политологов станет ясным и многогранным.

DOI: $10.17976 /$ jpps/2019.03.12

\title{
THIRTY THREE ANGLES OF POLITICAL REALITY
}

\section{S.K. Oznobishchev ${ }^{1}$}

${ }^{1}$ Primakov National Research Institute of World Economy and International Relations (IMEMO), Russian Academy of Sciences. Moscow, Russia

OZNOBISHCHEV, Sergey Konstantinovich, Cand. Sci. (Hist.), Head of the Division, Primakov National Research Institute of World Economy and International Relations, Russian Academy of Sciences, Moscow, email: serko96@gmail.com Oznobischev S.K. Thirty Three Angles of Political Reality. - Polis. Political Studies. 2019. No. 3. P. 186-191. (In Russ.) https://doi.org/10.17976/jpps/2019.03.12

Received: 04.03.2019. Accepted: 18.03.2019

\begin{abstract}
This article analyses a panoramic spectrum of methodological approaches to the study of political processes and political reality, reacting to the publication of the Handbook "Modern Political Science: Methodology" that incorporates chapters prepared by the thirty three leading Russian political scientists. The authors observe a gradual, but more and more decisive, retreat from the formerly dominating principles of the Marxist methodological paradigm in modern Russian political science. Directions, and the scale of application and implementation within the political science in modern Russia of key methodological paradigms of world political science, include: positivism, behaviorism, structuralism, system analysis, constructivism, etc. A conclusion is made regarding the "mosaic" or composite character of methodological grounds of most of Russian political science schools and books, and the almost complete absence of "pure" methodological lines. The article leads the reader towards the conclusion that political science in Russia is reaching not quite methodological maturity and unity, but at least wide methodological pluralism, enabling researchers to apply in their studies all main worldly spread methodological achievements and paradigms.
\end{abstract}

Key words: methodology, political science, sub-disciplines, Marxism, positivism, behaviorism, constructivism, conflict studies, political realism, institutionalism, scientific paradigm.

\section{References}

Box-Steffensmeier J., Brady H.E., Collier D. 2008. The Oxford Handbook of Political Methodology. Oxford: Oxford University Press.

Gaman-Golutvina O. 2008. Changes in Elite Patterns. - Europe-Asia Studies. Vol. 60. No. 6. P. 1033-1051. https://doi.org/10.1080/09668130802180967

Gaman-Golutvina O. 2009. Elites and Leadership in Russian Politics. - The Ashgate Research Companion to Political Leadership. Ed. by J. Masciulli, M.A. Molchanov, W.A. Knight. Ashgate: Ashgate Publishing Company. P. 269-287.

Gaman-Golutvina O. 2010. Russian Society and Elites in 1989-2009: Transformation Results and Future Perspectives. - Historical Social Research. Vol. 35. No. 2. P. 41-53. https://doi.org/10.12759/hsr.35.2010.2.41-53.

Gaman-Golutvina O. 2014. Parliamentary Representation and MPs in Russia: Historical Retrospective and Comparative Perspective. - Parliamentary Elites in Central and Eastern Europe. Ed. by E. Semenova, M. Edinger, H. Best. London; New York: Routledge. P. 241-260.

Gaman-Golutvina O. 2018. Political Elites in the USA under George W. Bush and Barack Obama: Structure and International Politics. - Historical Social Research. Vol. 43. No. 4. P. 141-163. https://doi. org/10.12759/hsr.43.2018.4.141-163

Goodin R. 2009. The Oxford Handbook of Political Science. Oxford: Oxford University Press. 1291 p. http://www.doi.org/10.1093/oxfordhb/9780199604456.001.0001 
Keman H., Woldendorp J.J. 2016. Handbook of Research Methods and Applications in Political Science. Cheltenham: Edwar Elgar Publishing.

Marsh D., Stoker G, Lowndes V. 2017. Theory and Methods in Political Science. London: Palgrave Macmillan.

Nikitin A. 2010. Nuclear Disarmament in a Non-Proliferation Context: a Russian Perspective. - Strategic Analysis. Vol. 34. No. 2. P. 202-212. https://doi.org/10.1080/09700161003592908

Nikitin A.I., Loukas M.A. 2008. Peace Support in the New Independent States: Different from the Rest? - Peace Operations: Trends, Progress, and Prospects. Ed. by Donald C.F. Daniel, P. Taft, S. Wiharta. Washington, D.C.: Georgetown University Press. P. 137-152.

Research and Method. 2006. New York: New York University Press.

Shapiro I., Smith R.M., Masoud T.E. 2004. Problems and Methods in the Study of Politics. Cambridge University Press.

Gaman-Golutvina O.V. 2016a. Political Science as a Meta-Disciplinary Matrix. - International Processes. Vol. 14. No. 1 (44). January-March. P. 86-94. (In Russ.) http://www.doi.org/10.17994/IT.2016.14.1.44.7

Gaman-Golutvina O.V. 2016b. Political Science Facing the Challenges of Modern Politics. To the 60th Anniversary of RPSA / SPSA. - Polis. Political Studies. No. 1. P. 8-28. (In Russ.) www.doi.org/10.17976/ jpps/2016.01.02

Institutsional'naya politologiya: Sovremennyi institutsionalizm i politicheskaya transformatsiya Rossii [Institutional Political Science: Modern Institutionalism and Political Transformation of Russia]. 2006. Ed. by S.V. Patrushev. Moscow: ISP RAS.

Mir politicheskoi nauki. Kategorii [The World of Political Science. Categories]. 2006. Ed. by A.Yu. Melville. Moscow: Prosveshchenie. (In Russ.)

Nikitin A.I. 2016. United Nations Peace Operations: Reconsidering the Principles, Reforming the Practice. - World Economy and International Relations. Vol. 60. No. 3. P. 16-26. (In Russ.) URL: https:// www.imemo.ru/jour/meimo/index.php?page_id=1248\&file=https://www.imemo.ru/files/File/magazines/ meimo/03 2016/16 26 NIKITIN.pdf (accessed 29.03.2019).

Politicheskaya nauka v Rossii: problemy, napravleniya, shkoly (1990-2007) [Political Science in Russia: Problems, Directions, Schools (1990-2007)]. 2008. Ed. by O.Yu. Malinova. Moscow: ROSSPEN. (In Russ.)

Rossiiskaya politicheskaya nauka. Istoki i perspektivy. V 5 t. [Russian Political Science. Origins and Prospects. In 5 vol.]. 2015. Ed. by O.V. Gaman-Golutvina. Moscow: Aspect Press. (In Russ.)

Rossiiskaya politicheskaya nauka. V 5 t. [Russian Political Science. In 5 vol.]. 2008. Ed. by A.I. Soloviev. Moscow: ROSSPEN. (In Russ.)

Sovremennaya politicheskaya nauka: Metodologiya [Modern Political Science: Methodology]. 2019. Ed. by O.V. Gaman-Golutvina, A.I. Nikitin. Moscow: Aspect Press. (In Russ.)

Sravnitel'naya politologiya [Comparative Political Science]. 2015. Ed. by O.V. Gaman-Golutvina. Moscow: Aspect Press. (In Russ.)

Strukturnye transformatsii i razvitie otechestvennykh shkol politologii [Structural Transformations and Development of Domestic Schools of Political Science]. 2015. Ed. by O.V. Gaman-Golutvina. Moscow: Aspect Press. (In Russ.)

\section{Литература на русском языке}

Гаман-Голутвина О.В. 2016а. Политология как метадисциплинарная матрица. - Международные процессы. Т. 14. № 1 (44). Январь-март. P. 86-94. http://www.doi.org/10.17994/IT.2016.14.1.44.7

Гаман-Голутвина О.В. 2016b. Политическая наука перед вызовами современной политики. Полис. Политические исследования. 2016. № 1. С. 8-28. www.doi.org/10.17976/jpps/2016.01.02

Институциональная политология: Современный институционализм и политическая трансформация России. 2006. Под ред. С.В. Патрушева. М.: ИСП РАН.

Мир политической науки. Категории. 2006. Отв. ред. А.Ю. Мельвиль. Москва: Просвещение.

Никитин А.И. 2016. Миротворчество ООН: обновление принципов, реформирование практики. - Мировая экономика и международные отношения. T. 60. № 3. C. 16-26. URL: https://www. imemo.ru/jour/meimo/index.php?page_id=1248\&file=https://www.imemo.ru/files/File/magazines/ meimo/03_2016/16_26_NIKITIN.pdf (accessed 29.03.2019).

Политическая наука в России: проблемы, направления, школы (1990-2007). 2008. Отв. ред. О.Ю. Малинова. Москва: РОССПЭН.

Российская политическая наука. 2008. В 5 т. Отв. ред. Соловьев А.И. Москва: РОССПЭН.

Российская политическая наука. Истоки и перспективы. В 5 т. 2015. Отв. ред. О.В. Гаман-Голутвина. Москва: Аспект Пресс.

Современная политическая наука: Методология. 2019. Отв. ред. О.В. Гаман-Голутвина, А.И. Никитин. Москва: Аспект Пресс.

Сравнительная политология. 2015. Отв. ред. О.В. Гаман-Голутвина. Москва: Аспект Пресс.

Сттруктурные трансформации и развитие отечественных икол политологии. 2015. Отв. ред.

О.В. Гаман-Голутвина. Москва: Аспект Пресс. 